\title{
DIVERSE APPROACHES TO THE MULTIDIMENSIONAL ASSESSMENT OF INNOVATION IN THE EUROPEAN UNION
}

\author{
Elżbieta ROSZKO-WÓJTOWICZ - Jacek BIAŁEK
}

(Received: 22 December 2017; revision received: 9 June 2018; accepted: 15 June 2018)

\begin{abstract}
The paper concentrates on the evaluation of the Global Innovation Index, the Summary Innovation Index and the Innovation Output Indicator. For the purpose of this article, the PROFIT (PROpertyFITting) method, an extension of the multidimensional scaling (MDS), was applied. The ultimate goal of MDS techniques is to produce a geometric map that illustrates the underlying structure of complex phenomena such as the innovation performance of the EU countries. Cluster analysis, conducted with the use of Ward's method provided an objective view of the division of the EU countries based on their selected characteristics. The final result is a two-dimensional map illustrating the structure of innovation performance. The main conclusion drawn from the analysis is the explanation of distance between single indices in a spatial map and their role in distinguishing specific groups of the EU countries from the perspective of innovation performance.
\end{abstract}

Keywords: multidimensional scaling (MDS), property fitting method (PROFIT), clustering, innovation intensity, EU member countries, synthetic measures of innovativeness

JEL classification indices: A11, A14, B16

Elżbieta Roszko-Wójtowicz, corresponding author. Assistant Professor, Department of Economic and Social Statistics, Faculty of Economics and Sociology, University of Lodz, Poland.

E-mail: elzbieta.roszko@uni.lodz.pl.

Jacek Bialek, Associate Professor, Department of Statistical Methods, University of Lodz, Poland. E-mail: jbialek@uni.lodz.pl. 


\section{INTRODUCTION}

In recent years, an unwavering interest in the measurement of innovativeness has been observed. This issue is assessed, among others, by the experts of the European Commission, which oversees the work on the publication of the Innovation Union Scoreboard and the Innovation Output Indicator. As a consortium, the Johnson Cornell University, INSEAD ${ }^{1}$ and the World Intellectual Property Organisation (WIPO) also publish annual reports. However, questions are raised about the quality and the form of the information provided, its validity and reliability, and thus further dilemmas are born (Goldsmith - Foxall 2003; Hollanders - Van Cruysen 2008). One solution is to create a global ranking by using the Dodgson or Borda method (Roszko-Wójtowicz - Białek 2017). Another solution is to select the most valuable indices by observing the impact of all indices on forming distances between levels of innovativeness of the EU countries.

Following the second option, the main aim of this paper is to conduct a research on similarities and differences in innovation intensity across the EU member countries. In particular, influences of international indices and sub-indices on the classification obtained are evaluated. Our research hypothesis is that the degree of specialisation of an innovation index has a significant influence on the location/position of the EU Member States on a perceptual map. For the purpose of this analysis, it has been assumed that the type and number of variables and the number of partial aggregates (sub-indices) included in the construction of the final innovation index determine the degree of index specialisation. In the theory, specialisation refers to the concentration of productive efforts on a rather limited range of tasks to gain greater degrees of efficiency (von Schutz - Stierle 2003; Aiginger 2004). Adapting the term "specialisation" to the needs of this article, we equate the narrow specialisation of an innovation index with a high level of concentration of an index. The narrow specialisation assumption is met by an index based on a small number of variables. In addition, concentration means that the main index consists of at most two separate sub-aggregates. Sub-indices must be calculated for independent thematic areas described by at least two variables. Thus, among the three innovation indices selected for this analysis - Global Innovation Index, Summary Innovation Index and Innovation Output Indicator, the last one of them proves to be an index characterised by a narrow specialisation and a high level of concentration.

For the purpose of this article, the PROFIT (PROpertyFITting) method, an extension of multidimensional scaling (MDS), was applied. MDS is used in many

1 INSEAD was originally an acronym for the French "Institut Européen d'Administration des Affaires" or European Institute of Business Administration. 
different fields, including economics (Black 1991), sociology (Beardsworth-Keil 1992) and political science (Lieske 1993). Similarly to the factor analysis, MDS can be applied to any data matrix, as long as the matrix elements provide information about the relations among objects, events, or behaviours (considered as stimuli) that include rows and columns of the matrix (Young - Hamer 1987). MDS is widely used to assess various socioeconomic events, ranging from social/ human views (Wish et al. 1970) to perceptions of visual patterns (Hirschberg et al. 1978). The ultimate goal of MDS techniques is to produce a geometric map that illustrates the underlying structure of complex phenomena, for instance, the innovativeness of the EU countries. The results obtained using the PROFIT method were compared to those obtained using hierarchical clustering of the countries based on the selected indices and sub-indices. Clustering was carried out not only among the countries but also their characteristics so that information was obtained, for example, on the similarity (in terms of the Euclidean distance) between innovation indices and sub-indices.

\section{LITERATURE REVIEW}

\subsection{Measurement of latent variables}

In practice, people are often faced with the need to measure phenomena (processes) that are not directly observable and measurable. In such a situation, indicators, which are measurable characteristics (properties) of a particular phenomenon, can be used. The occurrence of a proper observable and measurable characteristic is an evidence of the existence of another interesting phenomenon. In order to measure latent variables described by more than one indicator, it is necessary to aggregate these indicators according to a formative or reflexive approach (Panek 2015).

The starting point for constructing models with latent variables is to determine the character/nature of the relationships between the indicators and the theoretical variable selected for the analysis. The decision on the type of indicators to be included in the model should be taken on the basis of substantive premises, and the appropriate theoretical descriptions should provide validation for the adopted approach (Rogowski 1990).

In addition, it is often assumed that the analysed non-observable phenomenon is a set of specific sub-domains (sub-indices, pillars, areas of analysis). Sub-domains that are latent variables should be presented in an aggregated form which is a group index of a particular sub-domain that characterises the analysed phenomenon. As the next step, a synthetic index, measuring the latent phenomenon for aggregated sub-domains, should be constructed. 
The summary synthetic indices selected for the comparative analysis describe the phenomenon of innovativeness, and are widely known in the literature. Innovativeness is a phenomenon that is not directly observable and measurable; hence it belongs to the group of latent variables. The approach that uses formative indicators is dominant in the construction of international innovation indices analysed in this paper. Formative indicators are treated as determinants of the latent variable. A particular phenomenon, which is, for example, an element of economic development (its aspect), described by the latent variable, is shaped by specific indicators (in this case causality flows from the indicators to the latent variable), and which is a consequence of the occurrence of certain observable phenomena. An example of the model with formative indicators is the model describing the relationship between the variable (concept) of "technological level" and such indicators as R\&D expenditure (\% of GDP) and the number of patents applied for (per million inhabitants) that characterise it. These indicators have a causal effect on the variable.

If the number of patents registered per 1 million inhabitants increases, the technological level rises, even if the R\&D expenditure, expressed as a percentage of GDP, remains unchanged. At the same time, an increase in the technological level, e.g. due to increased R\&D spending, does not necessarily and automatically change the value of the latter indicator.

The evaluation of relevancy of the selection of formative indicators is most often conducted on the basis of theoretical assumptions or expert opinions (Rossiter 2002). Measurement tools using formative indicators are usually referred to as indices (Diamantopoulos - Winklhofer 2001). In the area of research on innovativeness of economies, such a model may form the basis for the construction

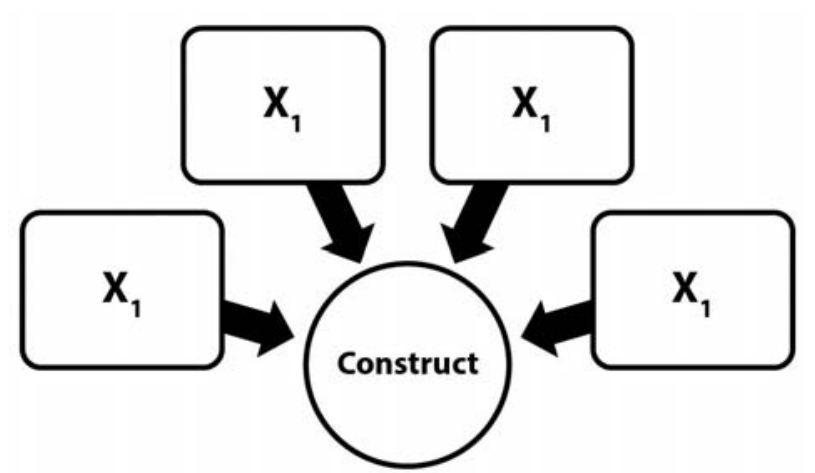

Figure 1. A model with formative indicators

Source: Own compilation based on Diamantopoulos - Siguaw (2006). 
of synthetic measures/indices. Indicators in such a model/approach need not to be homogeneous (relationships between indicators can be heterogeneous) (Smarandache - Savoiu 2015). However, compared to reflexive indicators, formative indicators are not interchangeable (Sagan 2011, 2013). This means that the elimination or addition of an indicator changes the nature of the measured construct. They are not explained by the measurement model (they are independent variables) and constitute a heterogeneous set of all the indicators related to a given latent variable. In the process of model specification, the entire "population" of formative indicators is taken into account. Due to the fact that these indicators act as independent variables in the measurement model, the assessment of alignment of the indicators is an important step in their construction. High alignment makes it difficult to determine causal effects of individual indicators in the formation of the latent variable and to assess the relevance of the indicator. Typically, such indicators form a composite indicator obtained by aggregation of objective or subjective indicators. In practice, the measurement model with formative indicators is based mostly on the Principal Component Analysis model (Maggino 2009).

\subsection{Measurement of innovativeness}

Our analysis is limited to three indices: the Global Innovation Index (GII), the Summary Innovation Index (SII) and the Innovation Output Indicator (IOI). Differences in the approach to the measurement of innovativeness in each of these indices have a significant impact on the final results of the ranking of countries.

One of the fundamental differences that can be observed is the degree of specialisation of the innovation indices.

Table 1. Comparative summary of selected indices

\begin{tabular}{l|c|c|c}
\hline & \multicolumn{3}{|c}{ Name of the indicator } \\
\cline { 2 - 4 } & $\begin{array}{c}\text { Global Innovation } \\
\text { Index (GII) }\end{array}$ & $\begin{array}{c}\text { Innovation Output } \\
\text { Indicator (IOI) }\end{array}$ & $\begin{array}{c}\text { Summary Innovation } \\
\text { Index (SII) }\end{array}$ \\
\hline Produced by ... & $\begin{array}{c}\text { JOHNSON Cornell } \\
\text { University - INSEAD } \\
- \text { WIPO }\end{array}$ & European Commission & European Commission \\
\hline Number of variables & 79 & 5 & 25 \\
\hline Number of countries & 141 & 38 & 34 \\
\hline Date of publication & Since 2007, annually & $\begin{array}{c}\text { Since 2010, 4-year } \\
\text { time frame }\end{array}$ & Since 2001, annually \\
\hline
\end{tabular}

Source: Own elaboration based on European Commission (2013, 2015); Vertesy - Deiss (2016); Dutta et al. (2015). 
The GII has the broadest coverage of variables. The $8^{\text {th }}$ edition of the report presented 141 economies, covering $95.1 \%$ of the population living worldwide and $98.6 \%$ of global GDP (US \$). In the construction of the ranking, 79 individual indicators that characterise innovativeness were included (Dutta et al. 2015). These indicators fall within the following three categories: quantitative (hard) data (55 indicators), composite indicators (19 indicators) and survey (soft) data (5 indicators). Preparing indicators before the index calculation is statistically justified, i.e. although there is no imputation of missing data, outliers (indicators with an absolute value of skewness greater than 2 or a kurtosis greater than 3.5) are detected and transformed by taking natural logs and special rescaling. All indicators are normalised into the $[0,100]$ range, with higher scores representing better outcomes. Normalisation was made according to the min-max method. The final GII is the simple weighted arithmetic mean of the Input and Output Subindex scores where weights are fixed and predefined.

As with GII, sub-indices were made up of a specific number of variables, the SII is also created for this index. Over the years, the methodology of calculating the SII has evolved, now 25 indicators, which have been assigned to one of the five categories, are used. The first three sets of indicators are variables from the input layer (17 indicators) and the last two include variables from the output layer ( 8 indicators). The input layer is described by: a) factors stimulating innovativeness (enablers), and b) company activities which show innovative activities implemented at the company level. The output layer is described by effects which reflect the results of innovative activities carried out in the sphere of business (European Commission 2015; Majerová 2015). Similarly to the GII, the SII methodology assumes outliers detection. Firstly, however, a different, two-sigma rule is used for this detection, and, secondly, outliers are replaced by the maximum or minimum (depending on the kind of outliers) values observed over all the years and in all the countries instead of log-transformation. Instead of that, the SII methodology detects indicators which are highly volatile and have skewness greater than 1. For the following indicators, data have been transformed using a square root transformation. If data for a year-in-between are missing, they are imputed with the value of the previous year. If data are not available at the beginning of the time series, they are imputed with the next available year. Finally, the re-scaled values of the country scores (after correcting for outliers and a possible transformation of the data) for all the years are calculated by first subtracting the minimum score and then dividing by the difference between the maximum and minimum scores. The $S I I$ is normalised to [0.1], i.e. the index is calculated as the unweighted average of the re-scaled scores for all the indicators, where these indicators receive the same weight ( $1 / 25$ if data are available for all 25 indicators). 
The IOI is undoubtedly the index characterised by the narrowest specialisation among the ones chosen for the comparative analysis. Only five variables can be isolated in the index, and only in one case, at a lower level of analysis, an aggregate variable is generated. This applies to competitiveness of the knowledgeintensive industries (with a high demand for specialist knowledge). The COMP component is defined as the arithmetic average (with equal weights) of two indicators: GOOD - the total value of exports of a country and SERV - the share of knowledge-intensive services in total services exports (European Commission 2013). The IOI was developed by the European Commission at the request of the European Council in order to benchmark national innovation policies and to monitor the EU's performance against its main trading partners. The last 2016 edition of the $I O I$ offers a number of novelties. It expands international coverage to Israel, New Zealand and Brazil (altogether 38 countries are now compared over a 4-year time frame). The first methodological difference in comparison to the previous measures is that the IOI is designed to be output-oriented. Secondly, the $I O I$ is a composite of only five components, chosen for their policy relevance, data quality, international availability, and cross-country comparability and robustness. The correlations between these indicators are analysed in the manual for $I O I$ and the analysis does not lead to data reduction. Moreover, the above-mentioned manual does not include outlier detection, which makes this methodology different from the two previous ones. The additional statistical information about the IOI methodology is that missing data are imputed by using the expectation-maximisation method, and all the indicators are standardised and transformed to be positive. Finally, the IOI is calculated as the weighted arithmetic mean of such normalised indicators and the obtained scores for countries are re-normalised to EU2011 = 100, for ease of communication. It is worth adding that none of these index methodologies use multivariate statistical methods for data selection and reduction (e.g.: factor analysis, discriminant analysis). For instance, it is quite unusual that there is no co-linearity verification in the GII methodology, although it is based on 79 indicators. There is no point in taking into consideration variables which are strongly correlated, thus the correlation analysis should play a role of data pre-selection. We also claim that taking fixed and arbitrary established weights must lead to anomalies since the weights should reflect the real impact (statistically measured) of the indicator on the innovativeness level. 


\section{METHODOLOGY}

\subsection{Conception of analysis}

The research was carried out according to the steps presented in Table 2.

Table 2. Research procedure

\begin{tabular}{|c|c|c|}
\hline No. & Description & Additional information \\
\hline Step 1 & Data collection & $\begin{array}{l}\text { Two separate datasets were created. The first one consists of } \\
\text { country scores and ranks according to the GII, SII and } I O I \text {. The } \\
\text { other one covers scores and ranks that the country achieved in } \\
\text { various sub-indices considered in the GII. }\end{array}$ \\
\hline \multirow{5}{*}{ Step 2} & \multirow{5}{*}{ Data transformation } & $\begin{array}{l}\text { a. Standardisation of the variables } \\
\text { Due to the varying range of variation of the innovation indices } \\
-S I I, I O I \text { and } G I I \text {, first the standardisation of the variables } \\
\text { according to the scheme corresponding to the zero unitarisation } \\
\text { method was carried out, i.e.: each } i \text {-th variable was transformed } \\
\text { as follows: }\end{array}$ \\
\hline & & $x_{i}-\min _{i}\left\{x_{i}\right\}$ \\
\hline & & $\max \left\{x_{i}\right\}-\min \left\{x_{i}\right\}$ \\
\hline & & $\begin{array}{l}\text { b. Creation of distance matrix } \\
\text { The distance matrix, which is the starting point for a com- } \\
\text { plementary cluster analysis, was created using the Euclidean } \\
\text { distance. Thus, understood distance for two normalised vectors } \\
X=\left(x_{1}, x_{2}, \ldots, x_{N}\right) \text { i } Y=\left(y_{1}, y_{2}, \ldots, y_{N}\right) \text { is determined according to the } \\
\text { formula: }\end{array}$ \\
\hline & & $d(x, y)=\sqrt{\sum_{i=1}^{N}\left(x_{i}-y_{i}\right)^{2}}$ \\
\hline Step 3a & $\begin{array}{l}\text { Multidimensional } \\
\text { scaling }\end{array}$ & $\begin{array}{l}\text { Then multidimensional scaling was performed using the Eucli- } \\
\text { dean distance, reducing the number of dimensions to two. }\end{array}$ \\
\hline Step $3 b$ & PROFIT analysis & $\begin{array}{l}\text { The last stage was the estimation of regression model param- } \\
\text { eters according to the PROFIT concept. In the application of } \\
\text { multivariate statistical methods/analysis, there is a large empha- } \\
\text { sis on the graphical display of the results. This is done here in } \\
\text { joint plots of objects (persons, groups, countries, or other enti- } \\
\text { ties) and variables, also called biplots (Gower - Hand 1996). }\end{array}$ \\
\hline Step 4 & Cluster analysis & $\begin{array}{l}\text { Clustering of variables was done using Ward's hierarchical } \\
\text { method with the Euclidean distances (see Section "Methods of } \\
\text { the Research"). As a consequence, the tree diagram (dendro- } \\
\text { gram) that illustrates the arrangement of the clusters produced } \\
\text { by hierarchical clustering was obtained. }\end{array}$ \\
\hline Step 5 & Results discussion & $\begin{array}{l}\text { Comparative analysis based on three selected indices - GII, } \\
\text { SII and IOI. Discussion of the results achieved from the Profit } \\
\text { analysis and Cluster analysis. }\end{array}$ \\
\hline
\end{tabular}

Source: Own elaboration. 
Application of MDS and the PROFIT method allowed us to obtain a perceptual map illustrating similarities of the EU countries in terms of their level of innovativeness and showing how individual innovation indices and sub-indices have contributed to the position of the individual countries on the map (Figures 2 and 5). Figures 3 and 6 show the so-called Shepard diagram that compares original distances between objects with distances visualised with the use of MDS. Tables 5 and 6 show the results of the estimation of regression model parameters. Tables 3 and 4 present the results for STRESS, normalised values of innovation indices for each EU country and coordinates of the countries' position on the perceptual map. As a result of cluster analysis, an accurate and objective division of the countries was achieved based on the selected characteristics of the clusters (Figures 4 and 6 ). In addition, it was possible to compare the classifications using each method and to formulate more concise conclusions.

\subsection{PROFIT analysis}

PROFIT is a kind of external vector analysis of preference mapping. The standard reason for using this method is testing hypotheses about attributes that influence people's judgement of similarities among a set of items. Nevertheless, there are no technical objections to use PROFIT for other cases, not related only to human preferences. The PROFIT method is a two-step procedure which is a combination of MDS and multiple regression analysis. To understand the idea of PROFIT, it is advisable to start from the description of MDS. MDS is a means of visualising the level of similarity of individual cases of a dataset (Borg - Groenen 2005). It refers to a set of related ordination techniques used in information visualisation, in particular, to display the information contained in a distance matrix. It is a form of non-linear dimensionality reduction (Kruskal - Wish 1978; Young - Hamer 1987). An MDS algorithm aims to place each object in $N$-dimensional space so that the between-object distances are preserved as well as possible. Each object is then assigned coordinates in each of the $N$-dimensions. The number of dimensions of an MDS plot $(N)$ can exceed 2 and is specified a priori. Choosing $N=2$ optimises the object locations for a two-dimensional scatterplot. MDS can have a metric or non-metric form and, as a rule, the non-metric MDS is used before the PROFIT analysis (Kruskal 1964; Takane et al. 1977). In such a case, the method finds both a non-parametric monotonic relationship between the dissimilarities in the item-item matrix and the Euclidean distances between items $d_{i j}$, and the location of each item in the low-dimensional space. The relationship is typically found using isotonic regression: let $x$ denote the vector of proximities, $f(x)$ is a monotonic transformation of $x$, and $d$ represents the point distances; then 
coordinates have to be found that minimise the so-called STRESS (Standardised Residual Sum of Squares) defined as follows (Kruskal 1964):

$$
\text { STRESS }=\sqrt{\frac{\sum_{i, j}\left(d_{i j}-f\left(x_{i j}\right)\right)^{2}}{\sum_{i, j} d_{i j}^{2}}},
$$

where lower indexes denote the $i-$ th and the $j$ - th point on the MDS map.

The lower the STRESS value, the better is the fit of the distance matrices reconstructed to the observed distance matrices. It is assumed that a very good fit occurs when the index takes a value in the range from 0 to 0.2 . It is assumed that STRESS values smaller than 0.1 correspond to an excellent representation of the data. When STRESS values are greater than 0.3 , results should be considered with some scepticism (Krzanowski 1988).

The PROFIT analysis evaluates the correspondence between one or more item attributes and the location of items in a multidimensional space. As it was abovementioned, PROFIT, which is a combination of MDS and multiple regression analysis, consists of two phases. After the first step (MDS), we obtain a configuration of $n$ points $x=\left(x_{1}, x_{2}, \ldots, x_{n}\right)^{T}$ in $r$-dimensional space ( $r$ is usually 2 or 3 ). In the second phase, PROFIT takes as input both a configuration of points $x$ and a set of attribute preferences data $p_{k}=\left(p_{k 1}, p_{k 2}, \ldots, p_{k n}\right)^{T}$, where $k=1,2, \ldots, m$ is the number of attributes (Zaborski - Pełka 2013). Then, a multiple regression analysis is performed using the coordinates as independent variables and the attributes as dependent variables. The procedure provides a separate regression for each attribute with "classical" regression coefficients:

$$
a_{k}=\left(x^{T} x\right)^{-1} x^{T} p_{k},
$$

where $x^{T}$ means the transpose of a matrix $x$.

We decided to use the PROFIT method for several reasons. First of all, from a technical point of view, there is a clear difference in the input data between PROFIT and PCA. PCA is based on a correlation matrix or a covariance matrix, while the PROFIT method takes a distance matrix as its starting point. These two different approaches may, although not necessarily, lead to different results. It is rare, however, that all pairs of highly correlated variables are simultaneously close in the sense of typical measures of distance (Euclidean, urban distance, etc.), which was also mentioned in the work cited above. Secondly, PCA is sensitive to data gaps, a lack of multidimensional normality of features used in the analysis (if statistical inference is needed) and a small volume of data (28 EU countries are not sufficient as it is often indicated that 50 observations are the ab- 
solute minimum). Thirdly, the undoubted advantage of the PROFIT method is the fact that it not only leads (similarly to PCA) to reduction of dimensionality (the number of variables) but also combines classical MDS with regression analysis. As a result, the PROFIT method allows us to identify factors (in our case, innovation indices) and to determine the direction of their impact on the distribution of the analysed objects (in our case the EU countries) on the perceptual map. It should be added that we have repeatedly used methods, such as PCA and CFA in our previous paper (Roszko-Wójtowicz - Białek 2017b), describing their advantages, disadvantages and limitations in the context of studying the innovativeness of the EU economies.

\subsection{Cluster analysis}

Generally, clustering is conducted for object class recognition by searching most homogeneous clusters (of the closest possible distance within the cluster and the maximum possible distance to other clusters). In particular, hierarchical clustering (also called hierarchical cluster analysis or HCA) is a method of cluster analysis which seeks to build a hierarchy of clusters (Kaufman - Rousseeuw 1990). Strategies for hierarchical clustering generally fall into two types (Rokach et al. 2005):

- Agglomerative: This is a "bottom up" approach: each observation starts in its own cluster, and pairs of clusters are merged as one moves up the hierarchy.

- Divisive: This is a "top down' approach: all observations start in one cluster, and splits are performed recursively as one moves down the hierarchy.

In general, the merges and splits are determined in a greedy manner. The results of hierarchical clustering are usually presented in a tree diagram (dendrogram). In our study, clustering of variables was done using Ward's hierarchical (Murtagh 2014; de Amorim 2015) method with the Euclidean distances. In the Ward's method, the distance between the new cluster and the rest of the clusters is computed as follows:

$$
d(i: j, k)=\alpha_{i,} d(i, k)+\alpha_{j} d(j, k)+\beta d(i, j),
$$

where: $d(i, j), d(i, k), d(j, k)$ are the pairwise distances between clusters $C_{i}, C_{j}$, and $C_{k}$ respectively,

$$
a_{m}=\frac{n_{m}+n_{k}}{n_{i}+n_{j}+n_{k}}
$$




$$
\beta=\frac{-n_{\kappa}}{n_{i}+n_{j}+n_{k}},
$$

and $n_{x}$ denotes the size of the $x$-th cluster.

\subsection{Research data}

Innovativeness can be measured by using many known indices, such as the GII (Dutta et al. 2015), the SII (European Commission 2015), and also the IOI, which was recently added by the European Commission (2013), Vertesy - Deiss (2016), as well as many others. Often these indices are based on different methodologies and take into consideration different sets of diagnostic variables. The final innovation index, and consequently the ranking of countries, is also influenced by the method of collecting data. For example, it is stated in the literature that one of the weaknesses of the $S I I$ is the fact that the variables used for the construction of the aggregate variable come from different time periods. It may be worth emphasising that aggregate variables are less susceptible to changes in time as they are based on several variables. Nevertheless, the final evaluation of innovativeness may strongly depend on the innovation index used. Due to this fact the data collection is based on information derived from specialised institutions that reliably describe the methodology applied, use data from public statistics and conduct periodical research. They create our social and economic reality, having an impact on people's decisions. As part of the research, institutions whose activities are related primarily to the development and publication of summary measurement indices have been identified and distinguished (JOHNSON Cornell University, INSEAD, WIPO, and European Commission). Table 3 shows the values of selected indices, the GII, SII and IOI, for each of the EU Member States following the normalisation procedure and the position of the country in the respective rankings. Input data were supplemented with the results of MDS, which is a first step in the PROFIT procedure (for detailed research procedure see Table 2). The last two columns contain information about the country's coordinates on the perceptual map. Table 4 presents the EU Member States' GII normalised sub-index values taking into account the position of each country in the respective rankings. In the case of innovation indices, the table also includes the results of MDS. 
Table 3. The innovativeness level in the EU Member States and the results of MDS along with the coordinates that determine the location of each country on the perceptual map

\begin{tabular}{|c|c|c|c|c|c|c|c|c|}
\hline \multirow{3}{*}{ Country name } & \multicolumn{8}{|c|}{ Final configuration: STRESS $=0.018$} \\
\hline & \multicolumn{2}{|c|}{ GII } & \multicolumn{2}{|c|}{$I O I$} & \multicolumn{2}{|c|}{ SII } & \multirow{2}{*}{ Dim 1} & \multirow{2}{*}{$\operatorname{Dim} 2$} \\
\hline & Value & Rank & Value & Rank & Value & Rank & & \\
\hline Austria (A) & 0.655 & 9 & 0.636 & 9 & 0.711 & 11 & 0.577 & -0.025 \\
\hline Belgium (BE) & 0.525 & 13 & 0.556 & 11 & 0.775 & 9 & 0.411 & 0.199 \\
\hline Bulgaria $(\mathrm{BG})$ & 0.164 & 24 & 0.112 & 26 & 0.046 & 27 & -1.356 & -0.138 \\
\hline Croatia (HR) & 0.145 & 25 & 0.154 & 25 & 0.203 & 23 & -1.127 & -0.065 \\
\hline Cyprus (CY) & 0.219 & 20 & 0.375 & 18 & 0.449 & 15 & -0.517 & 0.198 \\
\hline Czech Republic (CZ) & 0.542 & 12 & 0.480 & 13 & 0.453 & 14 & -0.043 & -0.146 \\
\hline Denmark (DK) & 0.805 & 7 & 0.855 & 6 & 0.993 & 2 & 1.314 & 0.193 \\
\hline Estonia (EE) & 0.603 & 11 & 0.359 & 19 & 0.531 & 13 & 0.014 & -0.311 \\
\hline Finland (FI) & 0.899 & 4 & 0.871 & 5 & 0.881 & 3 & 1.319 & 0.005 \\
\hline France (FR) & 0.635 & 10 & 0.719 & 8 & 0.721 & 10 & 0.654 & 0.096 \\
\hline Germany (DE) & 0.778 & 8 & 1.000 & 1 & 0.881 & 4 & 1.323 & 0.325 \\
\hline Greece (EL) & 0.086 & 26 & 0.277 & 23 & 0.299 & 21 & -0.963 & 0.193 \\
\hline Hungary (HU) & 0.198 & 21 & 0.515 & 12 & 0.308 & 20 & -0.590 & 0.394 \\
\hline Ireland (IE) & 0.864 & 5 & 0.884 & 3 & 0.791 & 8 & 1.194 & 0.026 \\
\hline Italy (IT) & 0.339 & 18 & 0.398 & 17 & 0.438 & 16 & -0.380 & 0.062 \\
\hline Latvia (LV) & 0.302 & 19 & 0.089 & 27 & 0.127 & 26 & -1.108 & -0.350 \\
\hline Lithuania (LT) & 0.168 & 23 & 0.000 & 28 & 0.146 & 25 & -1.338 & -0.315 \\
\hline Luxembourg (LU) & 0.860 & 6 & 0.882 & 4 & 0.817 & 6 & 1.201 & 0.035 \\
\hline Malta (MT) & 0.507 & 14 & 0.406 & 16 & 0.359 & 18 & -0.264 & -0.199 \\
\hline Netherlands (NL) & 0.965 & 3 & 0.566 & 10 & 0.827 & 5 & 0.987 & -0.507 \\
\hline Poland (PL) & 0.081 & 27 & 0.355 & 20 & 0.202 & 24 & -1.011 & 0.290 \\
\hline Portugal (PT) & 0.347 & 17 & 0.184 & 24 & 0.371 & 17 & -0.673 & -0.264 \\
\hline Romania (RO) & 0.000 & 28 & 0.304 & 22 & 0.000 & 28 & -1.428 & 0.347 \\
\hline Slovakia (SK) & 0.198 & 22 & 0.419 & 15 & 0.291 & 22 & -0.704 & 0.236 \\
\hline Slovenia (SI) & 0.425 & 16 & 0.445 & 14 & 0.615 & 12 & -0.017 & 0.119 \\
\hline Spain (ES) & 0.449 & 15 & 0.345 & 21 & 0.338 & 19 & -0.423 & -0.182 \\
\hline Sweden (SE) & 0.999 & 2 & 0.973 & 2 & 1.000 & 1 & 1.667 & 0.013 \\
\hline United Kingdom (UK) & 1.000 & 1 & 0.791 & 7 & 0.807 & 7 & 1.282 & -0.230 \\
\hline
\end{tabular}

Source: Own elaboration based on European Commission (2013, 2015); Vertesy - Deiss (2016); Dutta et al. (2015). 
政

\begin{tabular}{|c|c|c|c|c|c|c|c|c|c|c|c|c|c|c|c|c|c|c|c|c|c|c|c|c|c|c|c|c|c|c|c|}
\hline \multirow{16}{*}{ 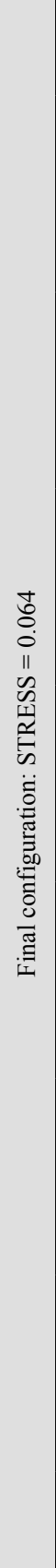 } & \multicolumn{2}{|l|}{$\stackrel{\sim}{\Xi}$} & $\begin{array}{l}\dot{8} \\
\dot{0} \\
\end{array}$ & $\begin{array}{c}-\overrightarrow{5} \\
\vdots \\
\end{array}$ & 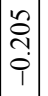 & $\begin{array}{c}\circ \\
\infty \\
\infty \\
\infty \\
0\end{array}$ & & $\begin{array}{l}\overrightarrow{0} \\
\vdots \\
0\end{array}$ & t. & $\begin{array}{l}\qquad \\
0 \\
0 \\
0\end{array}$ & & $\begin{array}{c}0 \\
0 \\
0 \\
0 \\
0\end{array}$ & $\begin{array}{l}\tilde{b} \\
0 \\
0 \\
\dot{9}\end{array}$ & 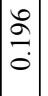 & $\frac{n}{9}$ & $\begin{array}{l}\stackrel{n}{n} \\
\stackrel{2}{0}\end{array}$ & & & $\begin{array}{l}\text { ôt } \\
\dot{0} \\
\dot{0}\end{array}$ & & & & & & & & & & & 㠻 & \\
\hline & \multicolumn{2}{|l|}{$\vec{\Xi}$} & $\begin{array}{l}\infty \\
0 \\
n \\
0 \\
1\end{array}$ & $\begin{array}{l}\vec{n} \\
\grave{n} \\
i\end{array}$ & $\begin{array}{l}\qquad \\
\pm \\
- \\
-\end{array}$ & $\begin{array}{c}0 \\
\dot{0} \\
\infty \\
0 \\
0\end{array}$ & $\begin{array}{l}\vec{\sigma} \\
0 \\
0\end{array}$ & $\begin{array}{c}\infty \\
\stackrel{1}{c} \\
\dot{9}\end{array}$ & $\begin{array}{l}\vec{J} \\
\underset{T}{T}\end{array}$ & $\begin{array}{l}n \\
\tilde{n} \\
\vdots \\
i\end{array}$ & 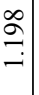 & $\begin{array}{l}\hat{8} \\
\dot{0} \\
\dot{\varphi}\end{array}$ & 守 & $\left|\begin{array}{c}n \\
n \\
n \\
i\end{array}\right|$ & $\stackrel{n}{\sigma}$ & $\dot{0}$ & 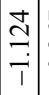 & $\begin{array}{l}\hat{b} \\
\stackrel{0}{0} \\
0\end{array}$ & \begin{tabular}{l|l}
$\infty$ & \\
$\infty$ & \\
0 &
\end{tabular} & $\begin{array}{l}0 \\
\vdots \\
\infty \\
\dot{\varphi} \\
\end{array}$ & & & & & 竎 & $\stackrel{\infty}{+\infty}$ & $\begin{array}{c}c \\
b \\
\vdots \\
1 \\
1\end{array}$ & & & \begin{tabular}{l}
0 \\
\hdashline \\
\hdashline \\
1
\end{tabular} & \\
\hline & \multirow{2}{*}{ 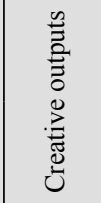 } & 荺 & $=$ & $\approx$ & 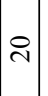 & $\infty$ & \pm & $a$ & $\infty$ & in & $\stackrel{\sim}{\sim}$ & $\curvearrowright$ & 은 & $\simeq$ & $\tilde{\lambda}$ & $\tilde{N}$ & $r$ & $\check{\sim}$ & $\vec{v}$ & - & 0 & & 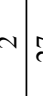 & & 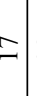 & 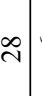 & 6 & & $\stackrel{ \pm}{\sim}$ & $m$ & \\
\hline & & 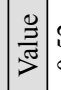 & $\tilde{n}$ & $\begin{array}{l}\circ \\
\stackrel{5}{\circ} \\
\circ\end{array}$ & \begin{tabular}{c} 
\\
\multirow{2}{*}{} \\
0 \\
0
\end{tabular} & ले & $\begin{array}{l}\tilde{\alpha} \\
\dot{\sigma} \\
0\end{array}$ & $\begin{array}{l}\overrightarrow{0} \\
\stackrel{2}{0} \\
0\end{array}$ & $\begin{array}{l}: \\
: \\
? \\
0\end{array}$ & \begin{tabular}{|}
$\hat{\widehat{O}}$ \\
$\stackrel{6}{0}$
\end{tabular} & $\begin{array}{l}+0 \\
\\
\\
\end{array}$ & 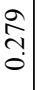 & 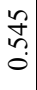 & $\mid \begin{array}{c}n \\
\tilde{o} \\
n \\
0\end{array}$ & 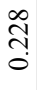 & $\begin{array}{l}\tilde{\hat{n}} \\
\stackrel{0}{0}\end{array}$ & $\mid \begin{array}{c}\vec{\sigma} \\
\stackrel{0}{0}\end{array}$ & $\begin{array}{l}\stackrel{a}{+} \\
\dot{0}\end{array}$ & $\begin{array}{l}\overrightarrow{7} \\
\stackrel{5}{0}\end{array}$ & & $\begin{array}{c}0 \\
\infty \\
\vdots \\
0\end{array}$ & & \begin{tabular}{c|c}
$\infty$ & \\
0 \\
$\infty$ \\
0 \\
0
\end{tabular} & & ?: & 0 & है & to & 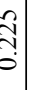 & $\begin{array}{l}\frac{1}{6} \\
0\end{array}$ & \\
\hline & \multirow{2}{*}{ 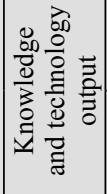 } & 前 & $\circ$ & 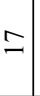 & $\infty$ & $\stackrel{\infty}{\sim}$ & $\infty$ & in & $a$ & $=$ & $\hat{\sim}$ & \pm & 6 & $\approx$ & $\stackrel{\Delta}{\sim}$ & $\stackrel{\sim}{2}$ & $m$ & $\simeq$ & $\approx$ & r & 2 & 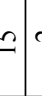 & $N$ & i) & $\mathrm{N}$ & $\approx$ & - & & $\vec{N}$ & 寸 & \\
\hline & & $\stackrel{0}{\Xi}$ & $\begin{array}{l}= \\
\bar{n} \\
0\end{array}$ & $\frac{\infty}{m}$ & ڤે̀े & & $\begin{array}{l}n \\
\vdots \\
0\end{array}$ & 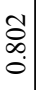 & $\begin{array}{l}\infty \\
\vdots \\
\vdots \\
0\end{array}$ & $\begin{array}{l}\bullet \\
\infty \\
\infty \\
0 \\
0\end{array}$ & 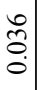 & \begin{tabular}{l}
2 \\
\multirow{2}{*}{} \\
0
\end{tabular} & $\begin{array}{l}\circ \\
\stackrel{0}{\circ}\end{array}$ & $\mid \begin{array}{l}\infty \\
\stackrel{0}{f} \\
\stackrel{0}{0}\end{array}$ & $\stackrel{0}{\frac{1}{7}}$ & 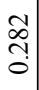 & $\mid \begin{array}{l}0 \\
: \\
\infty \\
0 \\
0\end{array}$ & $\begin{array}{l}\overrightarrow{0} \\
+ \\
0\end{array}$ & $\begin{array}{c}m \\
\hat{0} \\
0 \\
0\end{array}$ & \begin{tabular}{c|c}
$\tau$ & \\
$\delta$ & 0 \\
0 & \\
0 &
\end{tabular} & $\begin{array}{c}n \\
\infty \\
\\
0 \\
0\end{array}$ & & \begin{tabular}{c|c}
$\mathbb{N}$ & \\
$\infty$ \\
$\dot{0}$ & \\
\end{tabular} & & है. & 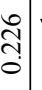 & - & & $\vec{n}$ & 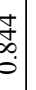 & \\
\hline & \multirow{2}{*}{ 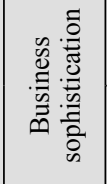 } & 茎 & $=$ & $r$ & $\stackrel{\sim}{\sim}$ & 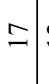 & $\simeq$ & 의 & $\infty$ & $m$ & $\stackrel{\infty}{\sim}$ & 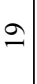 & $N$ & $a$ & तి & $\vec{\sim}$ & $m$ & - & $\eta$ & - & $\infty$ & & $n$ & S) & ปे & $\widehat{\imath}$ & 寸 & & $\mathrm{N}$ & 0 & \\
\hline & & $\stackrel{0}{\Xi}$ & 竎 & $\begin{array}{l}n \\
0 \\
0 \\
0 \\
0\end{array}$ & $\frac{9}{0}$ & 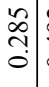 & 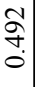 & 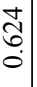 & $\begin{array}{l}\vec{f} \\
\dot{0}\end{array}$ & సิ & 0 & $\begin{array}{l}\vec{s} \\
\grave{0}\end{array}$ & 守 & $\mid \begin{array}{c}\widehat{\hat{\sigma}} \\
\stackrel{0}{0}\end{array}$ & $\underset{\text { J }}{\stackrel{0}{0}}$ & 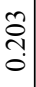 & $\left|\begin{array}{l}0 \\
\tilde{o} \\
\hat{\sigma}\end{array}\right|$ & लొ & $\begin{array}{l}\Re \\
\stackrel{0}{\circ}\end{array}$ & -1 & 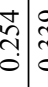 & & \begin{tabular}{c|c}
$c$ & \\
$\infty$ & \\
0 & \\
0
\end{tabular} & & $\begin{array}{c}m \\
\hat{n} \\
0 \\
\end{array}$ & $\begin{array}{l}2 \\
\stackrel{2}{0} \\
0\end{array}$ & $\begin{array}{l}\infty \\
\infty \\
\infty \\
0\end{array}$ & & 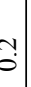 & $\begin{array}{l}\mathrm{E} \\
0 \\
0\end{array}$ & \\
\hline & \multirow{2}{*}{ 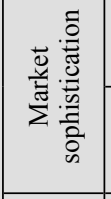 } & 离 & $=$ & \pm & $\stackrel{\sim}{\sim}$ & $\nabla$ & $=$ & $a$ & $N$ & $\because$ & तి & $m$ & $\infty$ & 으 & $\approx$ & $\hat{\imath}$ & in & ㄴ. & $\curvearrowright$ & $\simeq$ & $\infty$ & $\Delta$ & $r i$ & 3 & $m$ & 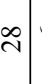 & 0 & & $\vec{N}$ & - & \\
\hline & & 墨 & \begin{tabular}{|l|}
$\circ$ \\
$\infty$ \\
$\vdots$ \\
$\vdots$ \\
0
\end{tabular} & $\begin{array}{l}\vec{n} \\
\tilde{0}\end{array}$ & $\begin{array}{c}\stackrel{I}{I} \\
\stackrel{0}{0} \\
\end{array}$ & $\begin{array}{l}n \\
\tilde{n} \\
0 \\
0\end{array}$ & $\begin{array}{l}\stackrel{n}{ \pm} \\
\stackrel{1}{0} \\
0\end{array}$ & 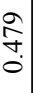 & $\begin{array}{l}\tilde{\imath} \\
\stackrel{0}{\circ}\end{array}$ & \begin{tabular}{|}
$\overrightarrow{\overrightarrow{1}}$ \\
$\tilde{0}$ \\
0
\end{tabular} & 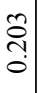 & $\begin{array}{l}\stackrel{a}{0} \\
\dot{0} \\
0\end{array}$ & $\begin{array}{l}a \\
\tilde{n} \\
o\end{array}$ & 胥 & . & $\begin{array}{l}\overleftarrow{J} \\
\vdots \\
0 \\
0\end{array}$ & $\begin{array}{l}n \\
\mathfrak{o} \\
0 \\
0\end{array} \mid$ & $\begin{array}{l}0 \\
\stackrel{0}{0} \\
\stackrel{0}{0}\end{array}$ & 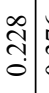 & $\begin{array}{c}0 \\
\stackrel{0}{n} \\
\vdots \\
0\end{array}$ & 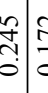 & \begin{tabular}{c|c}
1 & 5 \\
0 & \\
\end{tabular} & \begin{tabular}{l|l}
0 \\
$\vdots$ \\
$\vdots$ \\
$\vdots$
\end{tabular} & & : & 0 & $\begin{array}{l}\mathbf{y} \\
\hat{6} \\
0 \\
\end{array}$ & & $\begin{array}{l}0 \\
\vdots \\
0\end{array}$ & & \\
\hline & \multirow{2}{*}{ 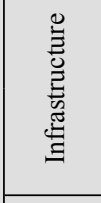 } & 茎 & $=$ & \pm & $\approx$ & $\stackrel{\infty}{\sim}$ & $\because$ & $a$ & 으 & $\nabla$ & $\approx$ & $m$ & $r$ & in & 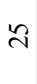 & $\approx$ & $\simeq$ & $\infty$ & तి & 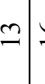 & 0 & $\bar{\sim}$ & 6 & ث & $=$ & $\hat{\imath}$ & $N$ & & 2 & - & \\
\hline & & $\stackrel{0}{\stackrel{\Xi}{二}}$ & $\dot{0}$ & 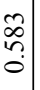 & $\begin{array}{l}\infty \\
\\
\end{array}$ & 0 & 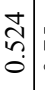 & $\begin{array}{l}n \\
\dot{0}\end{array}$ & $\vec{\sigma}$ & $\frac{a}{\sigma}$ & $\begin{array}{l}- \\
\stackrel{0}{+} \\
\dot{0}\end{array}$ & $\overrightarrow{\widehat{\sigma}}$ & $\begin{array}{c}\overrightarrow{\widetilde{D}} \\
0 \\
0\end{array}$ & $\frac{m}{\sigma}$ & ָิ & 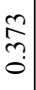 & $\begin{array}{l}2 \\
\hat{\sigma} \\
0 \\
0\end{array}$ & \begin{tabular}{l}
0 \\
$\stackrel{0}{\circ}$ \\
\hdashline
\end{tabular} & $\begin{array}{l}a \\
\vdots \\
+ \\
\dot{0}\end{array}$ & $\begin{array}{l}\vec{n} \\
\tilde{6} \\
0 \\
0\end{array}$ & $\begin{array}{l}\infty \\
0 \\
\vdots \\
0 \\
0\end{array}$ & $\begin{array}{l}0 \\
\vdots \\
\vdots \\
0 \\
0\end{array}$ & בְ. & ?: & : & $\begin{array}{l}\infty \\
\infty \\
0\end{array}$ & $\begin{array}{c}\mathbf{S} \\
\vdots \\
\vdots \\
\end{array}$ & & 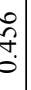 & - & \\
\hline & \multirow{2}{*}{ 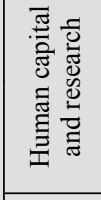 } & 屰 & & a) & $\hat{\sim}$ & 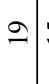 & $\because$ & 0 & $N$ & 6 & \pm & $\cong$ & - & $r$ & $\stackrel{ \pm}{\sim}$ & $\approx$ & 잉 & $\Xi$ & $\vec{\sim}$ & $\infty$ & ¿ & $\stackrel{\sim}{\sim}$ & $\infty ?$ & & $\approx$ & $\stackrel{\infty}{\sim}$ & $m$ & $\Xi$ & $\approx$ & + & \\
\hline & & 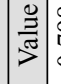 & 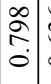 & 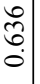 & 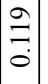 & $\begin{array}{l}n \\
\mathfrak{n} \\
m \\
0\end{array}$ & 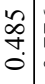 & $\begin{array}{l}0 \\
\stackrel{0}{\hat{0}} \\
0 \\
0\end{array}$ & $\begin{array}{l}\hat{\tilde{\sigma}} \\
\hat{\sigma}\end{array}$ & 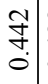 & $\begin{array}{l}\infty \\
0 \\
0 \\
0 \\
0\end{array}$ & $\begin{array}{l}\infty \\
0 \\
0 \\
0\end{array}$ & - & $\mid \begin{array}{c}\hat{f} \\
\hat{\theta}\end{array}$ & \begin{tabular}{l} 
in \\
\multirow{2}{*}{} \\
0
\end{tabular} & 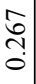 & $\begin{array}{c}\vec{b} \\
\dot{0} \\
\dot{2}\end{array}$ & $\begin{array}{l}\text { ț } \\
\text { ?. } \\
0\end{array}$ & $\begin{array}{c}n \\
0 \\
m \\
0\end{array}$ & 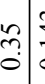 & $\frac{9}{0}$ & $\bar{\vdots}$ & 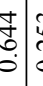 & $\frac{\hat{n}}{6}$ & 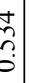 & 0 & 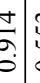 & & 导 & $\begin{array}{l}5 \\
0 \\
0 \\
\end{array}$ & \\
\hline & \multirow{2}{*}{ 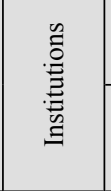 } & 茎 & in & a) & $\stackrel{\sim}{\sim}$ & $\because$ & $\stackrel{\infty}{-}$ & 의 & $N$ & $\simeq$ & $\stackrel{\infty}{\sim}$ & సి & - & $=$ & 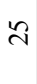 & $\stackrel{\Xi}{\sim}$ & $r$ & สี & $\tilde{\imath}$ & $\infty$ & $=\mathrm{I}$ & 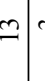 & $m s$ & 2 & \pm & $\widehat{\imath}$ & + & & $\vec{N}$ & 6 & ธ్ \\
\hline & & 墨 & \begin{tabular}{c|c}
$\mathfrak{g}$ \\
$\stackrel{f}{\circ}$ \\
$\stackrel{0}{0}$
\end{tabular} & ڤั) & 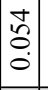 & \begin{tabular}{l|l}
$\stackrel{f}{\circ}$ \\
\end{tabular} & ָे. & 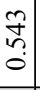 & $\begin{array}{l}\text { ¿े } \\
\vdots \\
0\end{array}$ & \begin{tabular}{l}
$\tilde{n}$ \\
\multirow{2}{*}{} \\
0
\end{tabular} & 0 & 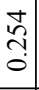 & - & \begin{tabular}{c}
2 \\
aे \\
\multirow{+}{0}{} \\
\end{tabular} & $\stackrel{m}{0}$ & $\begin{array}{l}\infty \\
\infty \\
0 \\
0\end{array}$ & \begin{tabular}{|c|}
$\infty$ \\
$\infty$ \\
0 \\
0 \\
0 \\
\end{tabular} & ְ̂. & $\begin{array}{l}0 \\
2 \\
\circ \\
\end{array}$ & $\begin{array}{l}n \\
n \\
n \\
0 \\
0\end{array}$ & 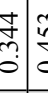 & 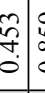 & $\begin{array}{l}0 \\
0 \\
0 \\
0 \\
0\end{array}$ & $\begin{array}{l}0 \\
?\end{array}$ & 守 & 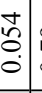 & م. & & तै & $\begin{array}{c}\hat{6} \\
\vdots \\
. \\
.\end{array}$ & $\begin{array}{l}\overline{\bar{J}} \\
\frac{\pi}{0} \\
\bar{\delta}\end{array}$ \\
\hline & $\overline{0}$ & & $|<|$ & & $|\tilde{m}|$ & ठે| & $\mid$ & 디 & 1 & $\mid$ II $\mid$ & 1 & +1 & |II & $|\vec{I}|$ & - & +1 & 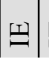 & -1 & $\exists$ & -1 & () & & 4 & & & 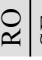 & s & & & & \\
\hline
\end{tabular}




\section{RESULTS AND DISCUSSION}

The results derived from the use of two methods, i.e. cluster analysis and MDS were compared. The first method allowed clustering of objects, in this case the EU countries, according to many characteristics simultaneously. The cluster analysis was performed twice. In the first case, clustering was carried out based on the combined effect of all the three innovation indices. In the second case, the impact of the GII sub-indices on the classification of the countries was assessed. MDS provided a perceptual map on which the EU countries were located. The smaller the distance between individual countries, the greater is their similarity based on all the characteristics analysed. The question regarding the selection of factors that determine the division obtained on the perceptual map was answered on the basis of the PROFIT results in which vectors showing the influence of particular characteristics on the obtained division were superimposed on the perceptual map.

In the paper, the PROFIT analysis was used to show how an input set of attributes (the values of the individual innovation indices) of the objects (the EU Member States) is visualised on the MDS axes. Coordinates assigned to the individual objects (countries) are considered as explanatory (independent) variables, while the values of individual attributes (innovation indices) of the objects are response (dependent) variables. The conducted analysis is aimed at providing information on how (in what direction) the individual objects (countries) are arranged on the plane based on the intensity of each of the selected input attributes. In order to do this, the estimation of the model parameters is performed by referring each attribute to the position of the objects on the MDS map.

The PROFIT analysis algorithm uses information about the coordinates (as independent variables) and the values of the objects relative to each of the individual attributes (as dependent variables) and conducts a multiple regression analysis. In the presented example, three regression analyses were performed as three attributes (variables) - SII, GII, IOI - were included in the MDS. The coordinates of the individual attributes (variables) were determined with the use of standardised regression coefficients corresponding to each of the MDS axes. After conducting the regression analyses for all the three innovation indices, the PROFIT analysis algorithm provides directional correlation coefficients determining the vector direction and sense that corresponds to each of the attributes selected to describe the dimensions. Thus three points with the following coordinates were determined on the MDS map: SII (Dim 1 - (0.978); Dim 2 - (0.036)), GII (Dim 1 - (0.959); Dim $2-(-0.269)$ ), and IOI (Dim 1 - (0.941); Dim $2-(0.298)$ ); the detailed results are presented in Table 1. The determined coordinates for the individual attributes allow showing how the EU member countries are arranged according to the intensity of a given attribute. In addition, it is worth noting that 


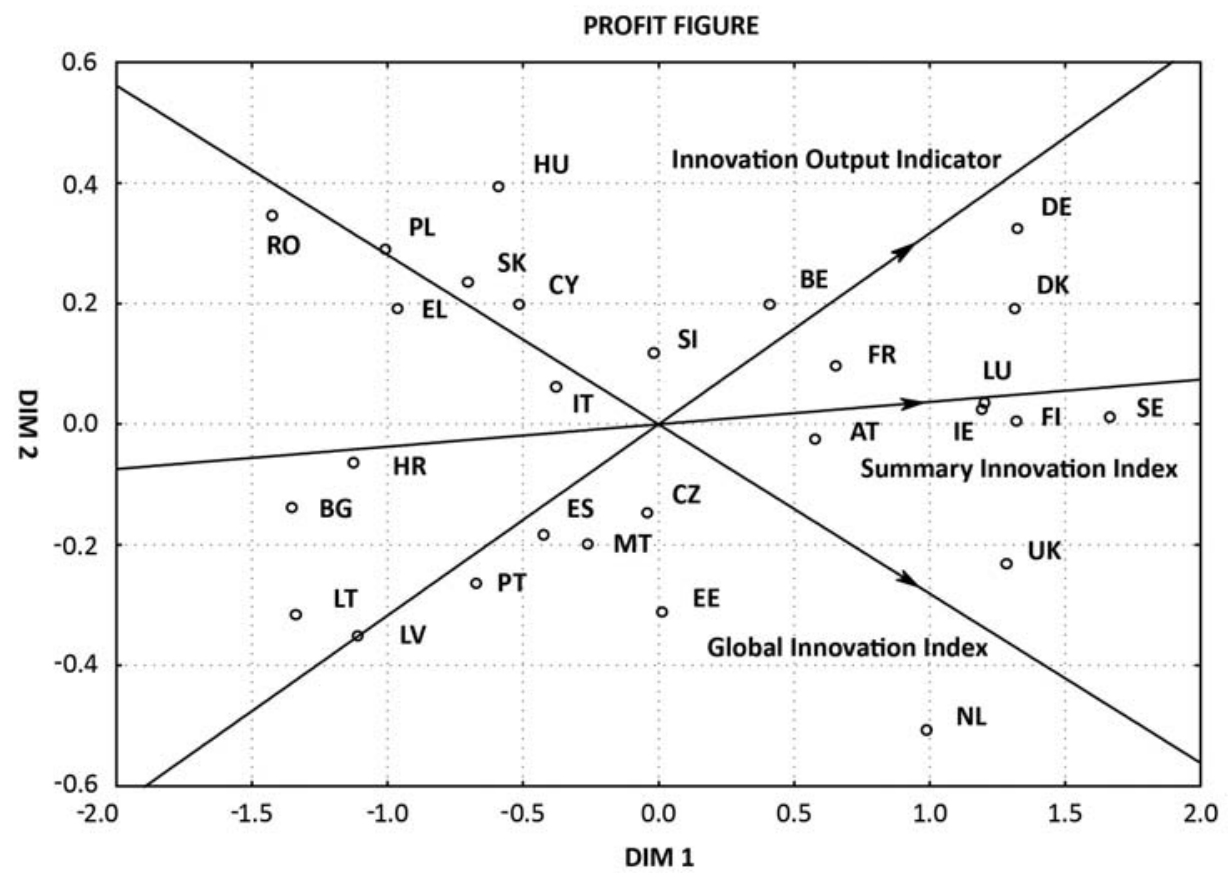

Figure 2. The perceptual map with vectors describing the individual dimensions of the plane

Source: Own elaboration based on European Commission (2013, 2015); Vertesy - Deiss (2016); Dutta et al. (2015).

the one-dimensional regression results for each of the indices were characterised by a fit at the level of no less than $95.5 \%$. From the point of view of $\mathrm{R}^{2}$ value, the GII was characterised as the best fit, then the IOI, followed by the SII. This indicates that the $G I I$ had the greatest influence on the obtained arrangement $\left(\mathrm{R}^{2}\right.$ $=99.3 \%$ ).

Moreover, observing the inclination angle of the vectors determined on the basis of the analysed innovation indices in relation to the axes connected with the dimensions (Dim 1 and Dim 2), it can be concluded that the SII index seems to be something of a resultant of measurements made with the $I O I$ and the GII indices. In turn, the latter two indices differ in terms of the direction of changes of the coordinate related to the second dimension, which may indicate that although they both measure innovativeness, their methodological differences will lead to noticeable differences in the assessment of the EU economies.

The Shepard diagram, which confronts distances based on the original data source with distances visualised in the MDS analysis (Figure 3), and the low 


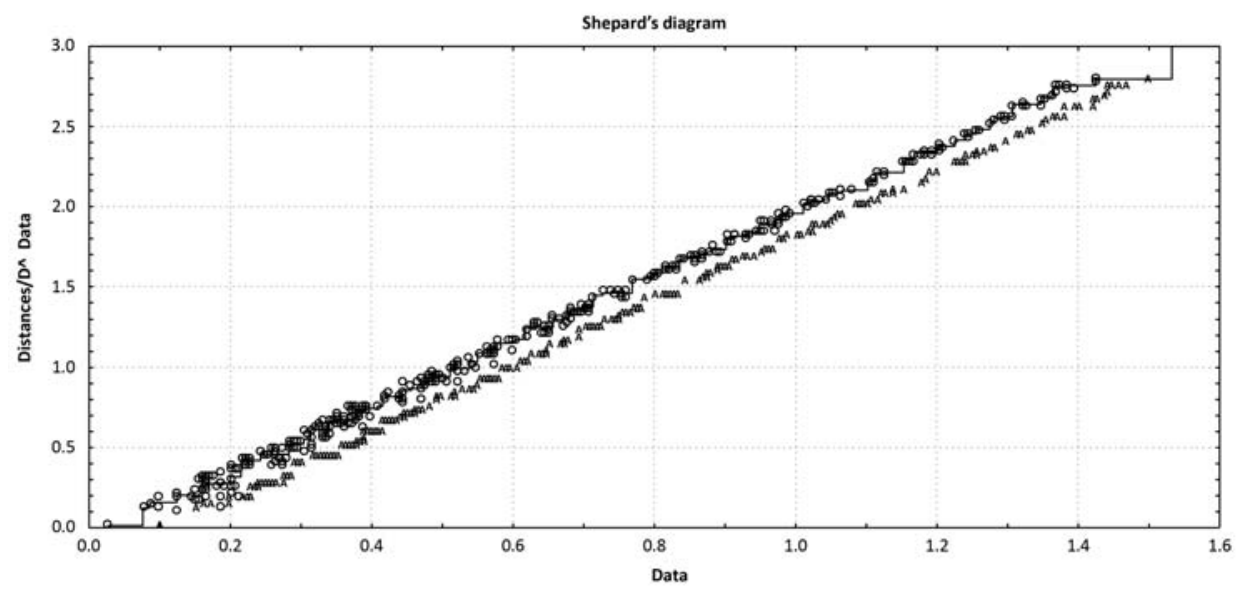

Figure 3. Shepard diagram illustrating the distances derived from the original data sources versus the distances reproduced in the MDS analysis

Source: Own elaboration based on European Commission (2013, 2015); Vertesy - Deiss (2016); Dutta et al. (2015).

value of STRESS $=0.0188$ indicate high efficiency of the MDS. In turn, the relevance of almost all the regression coefficients determined in the second stage of the PROFIT method and very high match rates of regression models (Table 5) indicate that the interpretation of the vectors determined on the perceptual map (Figure 2) is probably reflected in reality.

The analysis of the position of each country on the perceptual map (Figure 2 and Table 5) allows us to draw some detailed conclusions about similarities and differences between the EU countries from the point of view of the 3 analysed indices of innovativeness. A clear advantage of the PROFIT method is the fact that, despite a fairly complex calculation procedure, it enables an easy and clear interpretation of the results presented graphically. There is no doubt that Finland, Luxembourg and Ireland are the most similar in terms of all the three indices. The distances between these countries on the perceptual map are small (Figure 2). When analysing the results, it should be noted that the positions of the EU countries described by coordinates on the perceptual map are influenced by all the variables included in the analysis, i.e. all the three innovation indices combined. It can therefore be seen that, for example, Germany and Denmark are characterised by the highest intensity of $I O I$ value. The reproduction of the coordinates for Lithuania and Latvia on the line, where the $I O I$ vector lies, indicates that these countries have the worst results in terms of the variable in question. On the other hand, the Netherlands, the United Kingdom, and Sweden achieve the highest 
Table 5. Regression analysis for all the variables/dimensions of the evaluation

\begin{tabular}{|c|c|c|c|c|c|c|}
\hline \multirow{3}{*}{$\mathbf{N}=\mathbf{2 8}$} & \multicolumn{6}{|c|}{$\begin{array}{l}\text { Regression results for Innovation Output Indicator: } \mathrm{R}^{2}=0.9738 \text {; corrected } \mathrm{R}^{2}= \\
\qquad 0.9717\end{array}$} \\
\hline & \multicolumn{6}{|c|}{$F(2.25)=465.24 p<0.0000$ Estimation error: 0.04774} \\
\hline & $\mathbf{b}^{*}$ & $\begin{array}{c}\text { Std.error } \\
\text { b* }^{*}\end{array}$ & b & $\begin{array}{l}\text { Std.error } \\
\text { b }\end{array}$ & $\mathbf{t}(\mathbf{2 5})$ & $\mathbf{p}$ \\
\hline free coeff. & & & 0.498151 & 0.009021 & 55.21899 & 0.000000 \\
\hline Dim 1 & 0.949745 & 0.032351 & 0.269757 & 0.009277 & 29.07926 & 0.000000 \\
\hline Dim 2 & 0.298052 & 0.032351 & 0.356765 & 0.038724 & 9.21304 & 0.000000 \\
\hline \multirow{3}{*}{$\mathbf{N}=\mathbf{2 8}$} & \multicolumn{6}{|c|}{$\begin{array}{l}\text { Regression results for Summary Innovation Index: } \\
\qquad \mathrm{R}^{2}=0.9584 \text {; corrected } \mathrm{R}^{2}=0.9551\end{array}$} \\
\hline & \multicolumn{6}{|c|}{$F(2.25)=288.19 p<0.00000$ Estimation error: 0.06366} \\
\hline & $\mathbf{b}^{*}$ & Std.error b* & $\mathrm{b}$ & Std.error b & $\mathrm{t}(25)$ & $\mathrm{p}$ \\
\hline free coeff. & & & 0.513552 & 0.012031 & 42.68748 & 0.000000 \\
\hline Dim 1 & 0.978316 & 0.040778 & 0.296794 & 0.012371 & 23.99132 & 0.000000 \\
\hline Dim 2 & 0.036412 & 0.040778 & 0.046112 & 0.051641 & 0.89295 & 0.380402 \\
\hline \multirow{3}{*}{$\mathbf{N}=\mathbf{2 8}$} & \multicolumn{6}{|c|}{ Regression results for Global Innovation Index: $\mathrm{R}^{2}=0.9928$; corrected $\mathrm{R}^{2}=0.992$} \\
\hline & \multicolumn{6}{|c|}{$\mathrm{F}(2.25)=1746.5 \mathrm{p}<0.0000$ Estimation error: 0.02753} \\
\hline & $\mathbf{b}^{*}$ & $\begin{array}{c}\text { Std.error } \\
\text { b* }^{*}\end{array}$ & b & $\begin{array}{l}\text { Std.error } \\
\text { b }\end{array}$ & $\mathbf{t}(\mathbf{2 5})$ & $\mathbf{p}$ \\
\hline free coeff. & & & 0.491315 & 0.005202 & 94.4393 & 0.000000 \\
\hline Dim 1 & 0.959316 & 0.016860 & 0.304392 & 0.005350 & 56.8995 & 0.000000 \\
\hline Dim 2 & -0.269457 & 0.016860 & -0.356904 & -15.9822 & 0.89295 & 0.000000 \\
\hline
\end{tabular}

Source: Own elaboration based on European Commission (2013, 2015); Vertesy - Deiss (2016); Dutta et al. (2015).

results according to the GII. In relation to SII, the ranking of the Member States shows that Sweden, Germany, Denmark, and Finland are characterised by the highest intensity of innovation index values, while Lithuania, Bulgaria, Latvia, and Romania by the lowest intensity.

The cluster analysis performed is a valuable addition to the results obtained at the stage of application of the PROFIT method. The length of the branches visible on the dendrogram confirms that Ireland, Luxembourg and Finland form the closest cluster, similarly to Malta and Spain. Assessing the dendrogram, it is worth noting that the Netherlands, forming part of the cluster represented by Denmark, Germany, Sweden, Finland, Ireland, Luxembourg and the United Kingdom, is the farthest one out on the dendrogram. Similar conclusions can be drawn by reading the positions of the countries on the perceptual map. 
It should also be noted that the rankings based on the SII and the GII provide similar information. Thus, consequently, they show a relatively convergent order of the EU countries based on their level of innovativeness. The cluster analysis of the variables provides a confirmation of this statement (Figure 4). The comparison of the results of the PROFIT analysis with those of the cluster analysis of the variables does not allow us to draw clear conclusions. The sense of the vectors located on the perceptual map indicates the direction in which the value of the attribute that the vector represents increases. The cosines of the angles between the two vectors express the correlation between the attributes. The larger the angle between the vectors, the weaker is the correlation between the attributes. From the perceptual map, it can be seen that the SII and the IOI vectors are oriented in a similar direction, as opposed to the vector describing the GII. In addition, the strongest correlation occurs between the $I O I$ and the $S I I$, and between the SII and the GII. It is also worth noting that on the perceptual map the $S I I$ vector is located between the $I O I$ and the GII. This provides a basis for formulating conclusions about the impact of the degree of index specialisation on the final ranking of the countries.

In order to obtain a more detailed picture of the EU Member States' innovation level, the research procedure consisting of cluster analysis and PROFIT analysis was applied to all the GII sub-indices.
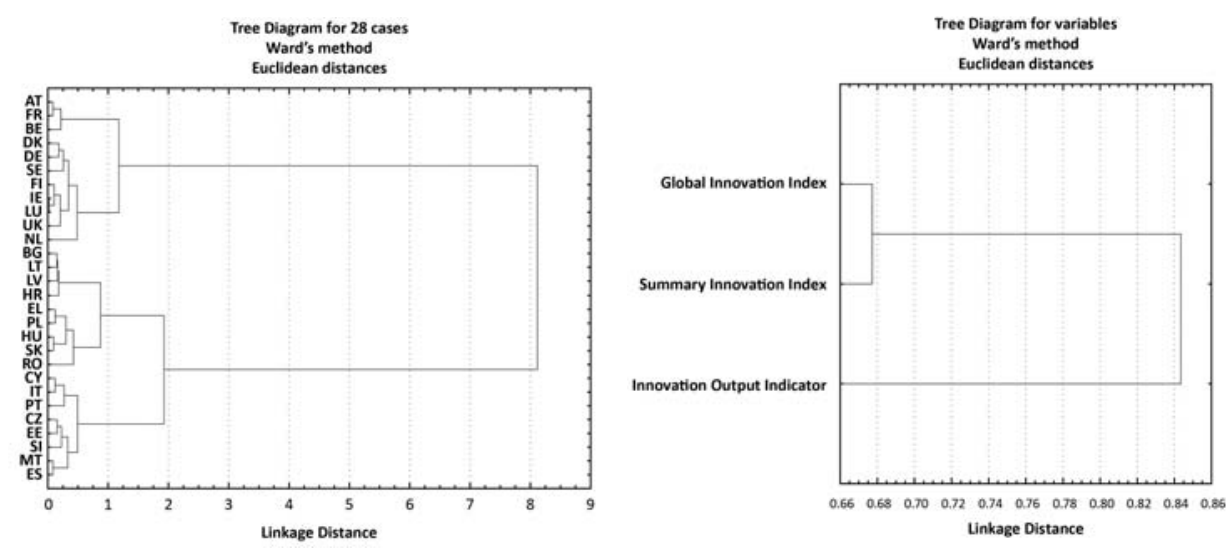

Figure 4. Dendrograms showing the results of the cluster analysis of the EU countries taking into account the three selected innovation indices

Source: Own elaboration based on European Commission (2013, 2015; Vertesy - Deiss (2016); Dutta et al. (2015). 
The value of the STRESS (Cox - Cox 1991), which evaluates the quality of the MDS procedure, shows that the fit of the distance matrices obtained from the original data source to the reproduced distance matrices is good (Table 4). Also, the Shepard diagram points to the high efficiency of the MDS. At the same time, this efficiency is undoubtedly lower than in the case of the analysis conducted for the three innovation indices. However, this situation has its justification in the number of the reduced dimensions, which were much more numerous in this case.

The presented biplot (Figure 5) graphically shows the relationship between the EU countries and their characteristics, i.e. the GII sub-indices. A single point on the perceptual map corresponds to one country. The distances between the points on the plane represent the distances between the countries in a multidimensional space. The countries that are at the bottom of the innovation rankings form the most homogeneous group, i.e. Slovakia, Hungary, Croatia, Bulgaria, Lithuania, Latvia, Poland, and Romania. It should be noted that Romania is the most removed from the other members of the cluster. Both the PROFIT analysis and the

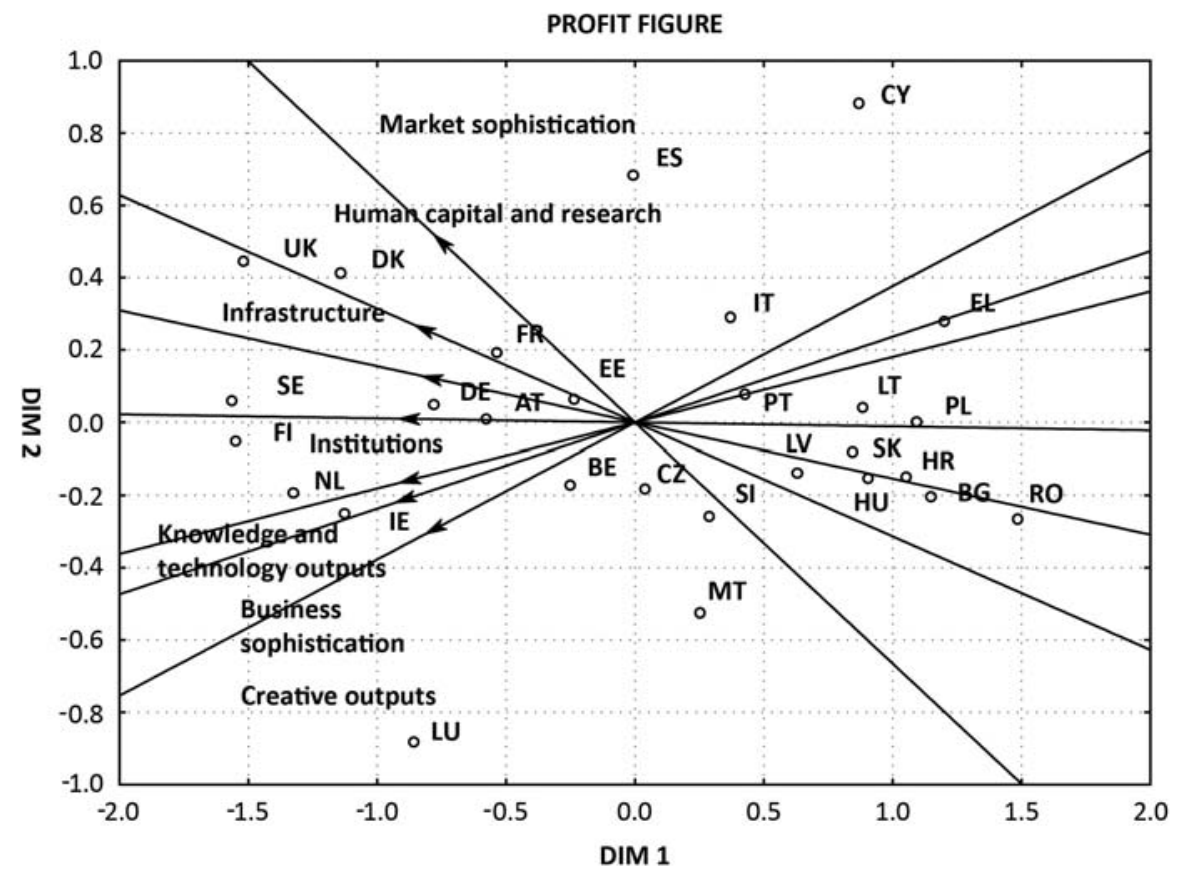

Figure 5. The perceptual map with vectors describing the individual dimensions of the plane GII sub-indices

Source: Own elaboration based on Dutta et al. (2015). 
cluster analysis confirmed that Hungary, Croatia and Bulgaria form the closest clusters. Assessing the location of the countries on the dendrogram (Figure 7), as well as in the biplot (Figure 5), it is worth noting Luxembourg and Cyprus, both of these countries are part of quite numerous clusters in which they are, however, the most outlying objects. The vectors on the perceptual map are the studied characteristics of the objects, i.e. individual sub-indices. Business sophistication as well as Knowledge and technology outputs are characterised by the strongest correlation with each other. On the perceptual map, the cosine of the angle between them is the smallest, as is the length of the branch visible on the dendrogram. In addition, the sense of these vectors indicates the same direction of growth of the values of these two characteristics. The more detailed analysis takes into account the characteristics for which the one-dimensional results of the regressions performed for each attribute were characterised by the fit at the level of at least $\mathrm{R}^{2}>0.8$ (Table 6). Thus, three sub-indices were eliminated. The following three characteristics had the greatest influence on the location of the countries on the

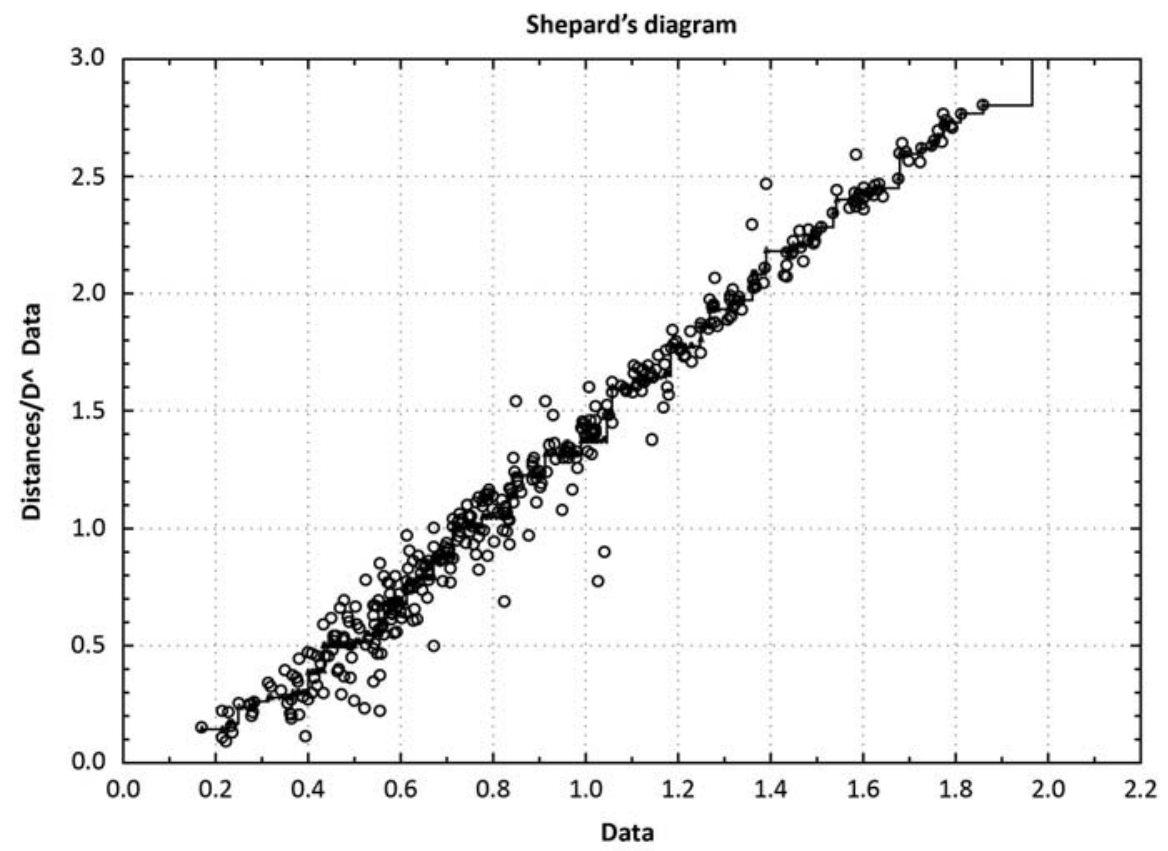

Figure 6. Shepard diagram illustrating the distances derived from the original data sources versus the distances reproduced in the MDS analysis - GII sub-indices

Source: Own elaboration based on Dutta et al. (2015). 
Table 6. Regression analysis for all the GII sub-indices

\begin{tabular}{|c|c|c|c|c|c|c|}
\hline \multirow[t]{2}{*}{$\mathrm{N}=\mathbf{2 8}$} & \multicolumn{6}{|c|}{$\begin{aligned} & \text { Regression results for: Institutions } \\
& \mathrm{R}^{2}=0.8389 ; \text { corrected } \mathrm{R}^{2}=0.8260 \\
\mathrm{~F}(2.25)= & 65.08 ; \mathrm{p}<.00000 ; \text { Estimation error: } 0.11299\end{aligned}$} \\
\hline & $\mathbf{b}^{*}$ & $\begin{array}{c}\text { Std. error } \\
\mathbf{b}^{*}\end{array}$ & b & $\begin{array}{c}\text { Std. error } \\
\text { b }\end{array}$ & $t(25)$ & $\mathbf{p}$ \\
\hline free coeff. & & & 0.436594 & 0.021353 & 20.4463 & 0.000000 \\
\hline Dim 1 & -0.915847 & 0.080280 & -0.259487 & 0.022746 & -11.4081 & 0.000000 \\
\hline Dim 2 & 0.010103 & 0.080280 & 0.007799 & 0.061979 & 0.1258 & 0.900865 \\
\hline \multirow[t]{2}{*}{$\mathrm{N}=\mathbf{2 8}$} & \multicolumn{6}{|c|}{$\begin{array}{l}\text { Regression results for: Human capital and research } \\
R^{2}=0.8036 \text {; corrected } R^{2}=0.7879 ; \\
F(2.25)=51.15 ; p<.00000 \text { Estimation error: } 0.12365\end{array}$} \\
\hline & $\mathbf{b}^{*}$ & $\begin{array}{c}\text { Std. error } \\
\mathbf{b}^{*}\end{array}$ & b & $\begin{array}{c}\text { Std. error } \\
\text { b }\end{array}$ & $t(25)$ & $\mathbf{p}$ \\
\hline free coeff. & & & 0.488737 & 0.023368 & 20.91489 & 0.000000 \\
\hline Dim 1 & -0.854941 & 0.088634 & -0.240100 & 0.024892 & -9.64574 & 0.000000 \\
\hline $\operatorname{Dim} 2$ & 0.269585 & 0.088634 & 0.206299 & 0.067827 & 3.04155 & 0.005463 \\
\hline \multirow[t]{2}{*}{$\mathrm{N}=\mathbf{2 8}$} & \multicolumn{6}{|c|}{$\begin{array}{c}\text { Regression results for: Infrastructure } \\
\quad \mathrm{R}^{2}=0.7028 ; \text { corrected } \mathrm{R}^{2}=0.6790 ; \\
\mathrm{F}(2.25)=29.56 ; \mathrm{p}<.00000 ; \text { Estimation error: } 0.15183\end{array}$} \\
\hline & $\mathbf{b}^{*}$ & $\begin{array}{c}\text { Std. error } \\
\text { b }^{*}\end{array}$ & b & $\begin{array}{c}\text { Std. error } \\
\text { b }\end{array}$ & $t(25)$ & $\mathbf{p}$ \\
\hline free coeff. & & & 0.582908 & 0.028693 & 20.31535 & 0.000000 \\
\hline Dim 1 & -0.828410 & 0.109031 & -0.232224 & 0.030564 & -7.59791 & 0.000000 \\
\hline Dim 2 & 0.128616 & 0.109031 & 0.098243 & 0.083283 & 1.17962 & 0.249254 \\
\hline \multirow[t]{2}{*}{$\mathrm{N}=\mathbf{2 8}$} & \multicolumn{6}{|c|}{$\begin{array}{l}\text { Regression results for: Market sophistication } \\
\quad \mathrm{R}^{2}=0.8779 ; \text { corrected } \mathrm{R}^{2}=0.8681 ; \\
\mathrm{F}(2.25)=89.88 ; \mathrm{p}<.00000 \text {; Estimation error: } 0.09181\end{array}$} \\
\hline & $\mathbf{b}^{*}$ & $\begin{array}{c}\text { Std. error } \\
\mathbf{b}^{*}\end{array}$ & b & $\begin{array}{c}\text { Std. error } \\
\text { b }\end{array}$ & $\mathbf{t}(25)$ & $\mathbf{p}$ \\
\hline free coeff. & & & 0.363793 & 0.017351 & 20.9663 & 0.000000 \\
\hline Dim 1 & -0.778920 & 0.069884 & -0.206009 & 0.018483 & -11.1460 & 0.000000 \\
\hline $\operatorname{Dim} 2$ & 0.520760 & 0.069884 & 0.375298 & 0.050363 & 7.4518 & 0.000000 \\
\hline \multirow[t]{2}{*}{$\mathbf{N}=\mathbf{2 8}$} & \multicolumn{6}{|c|}{$\begin{array}{l}\text { Regression results for: Business sophistication } \\
\quad \mathrm{R}^{2}=0.9126 \text {; corrected } \mathrm{R}^{2}=0.9056 ; \\
\mathrm{F}(2.25)=130.50 ; \mathrm{p}<.00000 \text {; Estimation error: } 0.08986\end{array}$} \\
\hline & $\mathbf{b}^{*}$ & $\begin{array}{c}\text { Std. error } \\
\mathbf{b}^{*}\end{array}$ & b & $\begin{array}{c}\text { Std. error } \\
\text { b }\end{array}$ & $t(25)$ & $\mathbf{p}$ \\
\hline free coeff. & & & 0.454358 & 0.016982 & 26.7559 & 0.000000 \\
\hline Dim 1 & -0.929390 & 0.059132 & -0.284311 & 0.018089 & -15.7173 & 0.000000 \\
\hline $\operatorname{Dim} 2$ & -0.220953 & 0.059132 & -0.184179 & 0.049290 & -3.7366 & 0.000971 \\
\hline
\end{tabular}


Table 6. continued

\begin{tabular}{|c|c|c|c|c|c|c|}
\hline \multirow[t]{2}{*}{$\mathbf{N}=\mathbf{2 8}$} & \multicolumn{6}{|c|}{$\begin{array}{l}\text { Regression results for: Knowledge and technology output } \\
\qquad \mathrm{R}^{2}=0.8616 \text {; corrected } \mathrm{R}^{2}=0.8506 \text {; } \\
\mathrm{F}(2.25)=77.84 ; \mathrm{p}<.00000 \text {; Estimation error: } 0.10690\end{array}$} \\
\hline & $\mathbf{b}^{*}$ & $\begin{array}{c}\text { Std. error } \\
\text { b }^{*}\end{array}$ & b & $\begin{array}{c}\text { Std. error } \\
\text { b }\end{array}$ & $t(25)$ & p \\
\hline free coeff. & & & 0.444832 & 0.020201 & 22.0199 & 0.000000 \\
\hline Dim 1 & -0.913307 & 0.074395 & -0.264174 & 0.021519 & -12.2764 & 0.000000 \\
\hline $\operatorname{Dim} 2$ & -0.165841 & 0.074395 & -0.130710 & 0.058636 & -2.2292 & 0.035023 \\
\hline \multirow[t]{2}{*}{$\mathrm{N}=\mathbf{2 8}$} & \multicolumn{6}{|c|}{$\begin{array}{c}\text { Regression results for: Creative output } \\
\quad \mathrm{R}^{2}=0.7547 ; \text { corrected } \mathrm{R}^{2}=0.7351 ; \\
\mathrm{F}(2.25)=38.46 ; \mathrm{p}<.00000 ; \text { Estimation error: } 0.12380\end{array}$} \\
\hline & $\mathbf{b}^{*}$ & $\begin{array}{c}\text { Std. error } \\
\text { b }^{*}\end{array}$ & b & $\begin{array}{c}\text { Std. error } \\
\text { b }\end{array}$ & $t(25)$ & $\mathbf{p}$ \\
\hline free coeff. & & & 0.439024 & 0.023395 & 18.76534 & 0.000000 \\
\hline Dim 1 & -0.812480 & 0.099055 & -0.204411 & 0.024921 & -8.20228 & 0.000000 \\
\hline$\overline{\operatorname{Dim} 2}$ & -0.307532 & 0.099055 & -0.210827 & 0.067907 & -3.10465 & 0.004689 \\
\hline
\end{tabular}

Source: Own elaboration based on Dutta et al. (2015).
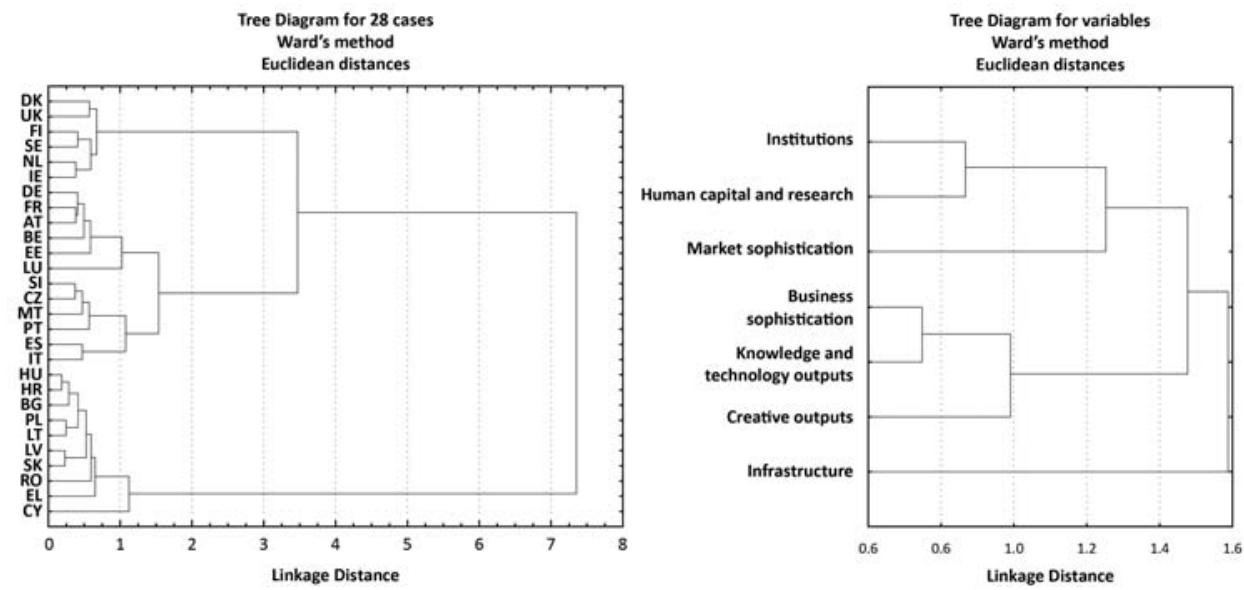

Figure 7. Dendrograms showing the results of the cluster analysis of the EU countries taking into account the GII sub-indices

Source: Own elaboration based on Dutta et al. (2015). 
perceptual map, i.e. Business sophistication $\left(\mathrm{R}^{2}-90.6 \%\right)$, Market sophistication $\left(\mathrm{R}^{2}-86.8 \%\right)$, and Knowledge and technology output $\left(\mathrm{R}^{2}-85.1 \%\right)$. The parameters of the regression models estimated for each of these characteristics for both dimensions are statistically significant.

\section{CONCLUSIONS}

The results of this research confirmed our starting hypothesis that the degree of specialisation of each innovation index/sub-index has a significant impact on the location/position of the EU Member States on the perceptual map. The applied statistical methods enabled the evaluation of the influence of international indices and sub-indices on the classification obtained. The original contribution of this article, compared to the researches published earlier, results primarily from the applied research procedure which combines MDS, including the PROFIT method, and cluster analysis. Listing and comparing the results derived from each method gave rise to a more reliable and credible formulation of the conclusions concerning the countries' innovation intensity. In particular, the results offer a contribution to the economic literature by: (1) providing a classification of the EU countries according to the similarities and differences in their innovation intensity, while taking into consideration many characteristics, (2) selecting those innovation indices/sub-indices that had the greatest influence on the distribution of the countries on the perceptual map, and (3) proposing a different look at international innovation rankings to show mutual relations between different synthetic indices.

This paper is also an attempt to provide a scientific contribution to the reconciliation of the measurement of innovativeness by focusing on more specialised/ narrow approach to the phenomenon. Further studies have to focus on the regular update of the results obtained with the use of the same research procedure to illustrate changes over time. The question concerning social or political implications of the conducted research also arises. As noted in the introduction, multidimensional statistics is widely used in the assessment of latent phenomena. Groups of decision makers at various levels of management attach importance to international rankings as a valuable source of information on the strengths and weaknesses of a given country. The image of a country's innovativeness shown from the perspective of one methodology may not be entirely reliable. The proposed approach provides an opportunity for a broader perspective concerning the assessment of latent phenomena. Due to this fact, the assessment of a country's innovation intensity is presented from many perspectives. The resulting image on the perceptual map as well as on the dendrogram reflects the actual situation better. 
Finding confirmation in our analyses, we expect that an increase in the specialisation of the synthetic index will lead to significant differences in the classification of countries. The broader the innovation perspective, which is expressed by the number of variables included in the synthetic assessment of latent phenomena, the smaller is the impact of each of them on the final ranking. This allows us to argue that the future work on measuring and assessing innovativeness should be focused rather on a narrower than broader picture of the phenomenon.

The PROFIT analysis, which combines two procedures, i.e. MDS and multiple regressions, allowed us to assess the similarity of the objects in terms of selected characteristics and to isolate those characteristics that have a key impact on the arrangement obtained. Thus, the PROFIT analysis resulted in an indication of the characteristics of the objects that determine the differentiation of the EU Member States and their location on the perceptual map. The MDS perceptual map outlines the configuration of the EU Member States according to a set of attributes, i.e. the GII innovation indices and sub-indices. The objects that were closer to each other on the perceptual map proved to be the most similar to each other. Nevertheless, a clear reference to the coordinate system of the MDS map of the variables that were the basis for determining the distances between the countries is very difficult. Therefore, the statistical procedure included a simultaneous application of PROFIT analysis and cluster analysis. Thus, it was assumed that the congruency of the findings provided by both applied methods is an indication of the accuracy of the results.

Nevertheless, the quality and reliability of the results can be deemed as high, which may arise from the fact that dimensionality reduction was not too drastic. In the case of innovation indices, it meant the transition from 3 dimensions ( 3 innovation indices) to 2 dimensions which are easy to interpret on the Cartesian perceptual map. With regard to sub-indices, compression was made based on 7 dimensions. The PROFIT analysis brings additional benefits beyond the ranking, as it allows to specify the clusters of countries with a similar level of innovativeness (e.g.: Poland on the MDS map is close to Slovakia, Hungary, Greece, and Romania, which means that unfortunately it is closer to the countries with a lower level of innovativeness, while the leaders, the Scandinavian countries, are naturally in the same cluster).

Finally, it might be worth adding that an additional incentive for the authors to reach for the PROFIT method was the fact that according to their state of knowledge at the time, no-one had used this method to analyse innovativeness before. This method may lead to a completely different assessment of countries' innovativeness compared to the competing methods (PCA, FCA, and others). In the case when there are differing rankings of objects (countries) obtained by means of different methods, one can always compromise by using the so-called grouping assessment methods, creating the "resultant ranking". 


\section{REFERENCES}

Aiginger, K. (2004): Industrial Specialisation and Geographic Concentration: Two Sides of the Same Coin? Journal of Applied Economics, VII(2): 231-248.

Beardsworth, A. - Keil, T. (1992): The Vegetarian Option: Varieties, Conversions, Motives and Careers. Sociological Review, 40(2): 253-293.

Black, J. K. (1991): Development in Theory and Practice: Bridging the Gap. Boulder, Colorodo: Westview.

Borg, I. - Groenen, P. (2005): Modern Multidimensional Scaling. Theory and Applications. Second Edition, New York: Springer Verlag.

Cox, T. F. - Cox, M. A. A. (1991): Multidimensional Scaling. London: Chapman and Hall.

de Amorim, R. C. (2015): Feature Relevance in Ward's Hierarchical Clustering Using the $\mathrm{L}_{p}$ Norm. Journal of Classification, 32(1): 46-62.

Diamantopoulos, A. - Siguaw, J. A. (2006): Formative vs. Reflective Indicators in Measure Development: Does the Choice of Indicators Matter? British Journal of Management, 17(4): 263282.

Diamantopoulos, A. - Winklhofer, H. M. (2001): Index Construction with Formative Indicators: An Alternative to Scale Development. Journal of Marketing Research, 38(2): 269-277.

Dutta, S. - Lanvin, B. - Wunsch-Vincent, S. (eds) (2015): The Global Innovation Index 2015. Effective Innovation Policies for Development. Fontainebleau, Ithaca, and Geneva: Cornell University, INSEAD, World Intellectual Property Organization (WIPO).

European Commission (2013): Commission Launches New Innovation Indicator. Brussels.

European Commission (2015): Innovation Union Scoreboard 2015. Belgium: Internal Market Industry, Entrepreneurship and SMEs, 2015. http://bookshop.europa.eu/en/innovation-unionscoreboard-2015-pbNBAY15001/.

Goldsmith, R. E. - Foxall, G. R. (2003): The Measurement of Innovativeness. Prague: MAC Prague Consulting Ltd.

Gower, J. C. - Hand, D. J. (1996): Biplots. London: Chapman \& Hall.

Hollanders, H. - Van Cruysen, A. (2008): Rethinking the European Innovation Scoreboard: A New Methodology for 2008-2010. Geneva: Pro INNO Europe.

Kaufman, L. - Rousseeuw, P. J. (1990): Finding Groups in Data: An Introduction to Cluster Analysis. New York: John\&Wiley.

Kruskal, J. B. (1964): Nonmetric Multidimensional Scaling: A Numerical Method. Psychometria, 29: $1-27$.

Kruskal, J. B. - Wish, M. (1978): Multidimensional Scaling. California: Sage.

Krzanowski, W. J. (1988): Principles of Multivariate Analysis: A User's Perspective. Oxford: Oxford University Press.

Maggino, F. (2009): The State of the Art in Indicators Construction in the Perspective of a Comprehensive Approach in Measuring Well-Being of Societies. Firenze: Firenze University Press.

Majerová, I. (2015): Measurement of Innovative Performance of Selected Economies of the European Union and Switzerland. International Journal of Information and Education Technology, 5(3): 228-232.

Lieske, J. (1993): Regional Subcultures of the United States. Journal of Politics, 55: 888-913.

Murtagh, F. (2014): Ward's Hierarchical Agglomerative Clustering Method: Which Algorithms Implement Ward's Criterion? Journal of Classification, 31: 274-295.

Panek, T. (2015): Hierarchiczny model pomiaru jakości życia (The Hierarchical Model of Life Quality Measures). Wiadomości Statystyczne, 6(649): 1-22. 
Rogowski, J. (1990): Modele miękkie. Teoria i zastosowanie w badaniach ekonomicznych (Soft Models. Theory and Application in Economic Research). Białystok: Wydawnictwo Filii UW w Białymstoku.

Rokach, L. - Maimon, O. (2005): Clustering Methods. In: Rokach, L. - Maimon, O. (eds): Data Mining and Knowledge Discovery Handbook. US: Springer, pp. 321-352.

Rossiter, J. R. (2002): The C-OAR-SE Procedure for Scale Development in Marketing. International Journal of Research in Marketing, 19(4): 305-335

Roszko-Wójtowicz, E. - Białek, J. (2017a): Application of Grouping Methods to Assess Growth and Development in the EU Member States. Acta Universitatis Lodziensis. Folia Oeconomica, 3(329): 193-211.

Roszko-Wójtowicz, E. - Białek, J. (2017b): Evaluation of the EU Countries Innovative Potential Multivariate Approach. Statistics in Transition - New series, 18(1): 167-180.

Sagan, A. (2011): Modele strukturalne w analizie zachowań konsumenta - ewolucja podejść (Structural Models in the Consumer Behaviour Analysis. Evolution of Approaches). Konsumpcja $i$ rozwój, 1: 67-76.

Sagan, A. (2013): Paradygmaty marketingu a modelowanie zmiennych ukrytych - porównanie modeli pomiarowych skali WSAW (Marketing Paradigms and Latent Variable Modelling - Comparison of Measurement Models of WSAW Scale). Zeszyty Naukowe UEK - Metody analizy danych, 909: 5-15.

Smarandache, F. - Savoiu, G. (2015): Neutrosophic Index Numbers: Neutrosophic Logic Applied in the Statistical Indicators Theory. Critical Review, XI: 67-100.

Statistics and Science (2013): A Report of the London Workshop on the Future of Statistical Sciences.

Takane, Y. - Young, F. - de Leeuw, J. (1977): Non-Metric Individual Differences Multidimensional Scaling: An Alternating Least Squares Method with Optimal Scaling Features. Psychometrika, 42(1): 7-67.

Vertesy, D. - Deiss, R. (2016): The Innovation Output Indicator 2016. Methodology Update. Brussels: European Commission.

Von Schutz, U. - Stierle, M. (2003): Regional Specialisation and Sectoral Concentration: An Empirical Analysis for the Enlarged EU. Document of European Regional Science Association.

Wish, M. - Deutsch, M. - Biener, L. (1970): Differences in Conceptual Structures of Nations: An Exploratory Study. Journal of Personality \& Social Psychology, 16(3): 361-373.

Young, F. W. - Hamer, R. M. (1987): Multidimensional Scaling: History, Theory and Application. New Jersey: Lawrence Eribaum Associates.

Zaborski, A. - Pełka, M. (2013): Geometrical Presentation of Preferences by Using Profit Analysis and R Program. Folia Oeconomia, Acta Universitatis Lodziensis, 285: 191-197. 